\title{
Seasonal development of lesions caused by Hymenoscyphus fraxineus on young Fraxinus excelsior trees in Latvia
}

\author{
Ilze Matisone, \\ Roberts Matisons, \\ Kristine Kenigsvalde, \\ Talis Gaitnieks, \\ Natalija Burneviča
}

\begin{abstract}
The spread of the ascomycete Hymenoscyphus fraxineus, causing dieback of common ash (Fraxinus excelsior) in Europe, is rapid and the damage is pronounced, as young ashes can perish over the course of only a few months following infection. The objective of this study was to investigate the rate and extent of lesion formation on young (5-8-year-old) ashes during a vegetation season in the hemiboreal zone in Latvia. Continuous surveys (with monthly intervals) of the health condition of 30 young ash and measurements of lesion area in three stands were performed during the vegetation season of 2015 . From June to September of that year, the number of observed lesions gradually rose from 58 to 87 . New lesions emerged on branches ( $55 \%, 0.5$ per tree), top shoots $(28 \%, 0.3$ per tree), and stems (17\%, 0.2 per tree), mostly appearing at the beginning of the observation period $(45 \%, 52 \%$, and $3 \%$ in June, July, and August, respectively). During the vegetation season, $20 \%$ of the existing and $28 \%$ of the newly-emerged lesions on branches, as well as $20 \%$ and $25 \%$ of top shoot lesions, respectively, reached the main stem. Some $(<$ $20 \%$ of cases) transitions of lesions from the tops and branches to the stems were observed. The extension of lesions was significant until August, and ceased afterwards in a similar fashion in all stands. The mean extension of area significantly differed between the previously-existing and newly-emerged lesions. During the vegetation season, the new lesions expanded by $25.1 \pm 4.8$ $\mathrm{cm}^{2}$, whereas the existing ones grew by only $7.3 \pm 1.1 \mathrm{~cm}^{2}$. The extension of the new lesions varied according to their location on a tree. The spread of emerging lesions on stems was considerably slower than on branches or top shoots $\left(1.9 \pm 0.7,7.3 \pm 1.5\right.$, and $14.5 \pm 4.1 \mathrm{~cm}^{2}$ per lesion per month, respectively). During the studied vegetation season (summer), the overall health score of trees decreased twice, yet the relationship between heath status and development of lesions lacked significance.
\end{abstract}

\section{Keywords: Common Ash, Ash Dieback, Lesion Length, Sapling Wilting}

\section{Introduction}

The ascomycete Hymenoscyphus fraxineus is a disease agent that has caused dieback of common ash (Fraxinus excelsior L.) in Europe in recent decades (Pautasso et al. 2013). Since the 1990s, ash dieback has been observed in Lithuania (Vasiliauskas et al. 2006) and Latvia (Laivinš et al. 2016), although in Latvia, it was only confirmed in 2007 (Kenigsvalde et al. 2010). The number of countries affected by ash dieback continues to increase and already exceeds 20 (Gross et al. 2014). This dieback affects stands of different ages and com- positions (Pliura \& Heuertz 2003, Schumacher et al. 2010), yet young stands are the most susceptible to infection, and hence are critical for development of the pathogen (Skovsgaard et al. 2010, Bengtsson et al. 2014).

The spread of $H$. fraxineus within its host is rapid, irrespective of tissue type, and proceeds in three dimensions (Schumacher et al. 2010). Some of the affected trees can be destroyed promptly, particularly as the fungus girdles the main stem, whereas others can have chronic symptoms (Thomsen \& Skovsgaard 2012, Pautasso et al. 2013).

Latvian State Forest Research Institute Silava, Rigas str. 111, Salaspils, LV-2169 (Latvia)

@ Ilze Matisone (ilze.matisone@silava.lv)

Received: Nov 16, 2016 - Accepted: Oct 23, 2017

Citation: Matisone I, Matisons R, Kenigsvalde K, Gaitnieks T, Burneviča N (2018). Seasonal development of lesions caused by Hymenoscyphus fraxineus on young Fraxinus excelsior trees in Latvia. iForest 11: 17-23. - doi: 10.3832/ifor2283-010 [online 2018-01-09]

Primary symptoms of the disease are macroscopic cankers on leaves and leafstalks (Skovsgaard et al. 2010), brown spots on buds (Bengtsson et al. 2014), and wilting of leaves and/or top shoots (Schumacher et al. 2010). These symptoms are followed by the formation of necrotic lesions spreading along rachises onto shoots, branches, and stems, resulting in dieback of the affected parts of a tree (Bakys et al. 2009, Skovsgaard et al. 2010, Bengtsson et al. 2014). Skovsgaard et al. (2010) noted, however, that cankers may also appear before wilting and dieback of shoots occurs. The appearance of lesions on undamaged stems suggests that the fungus could have entered through the lenticels (Husson et al. 2012). In addition, several strains of the fungus can attack a host simultaneously (Bengtsson et al. 2014). After dieback of the primary shoots, the affected trees can recover growth by formation of epicormic shoots, resulting in a bushy appearance of tree crowns (Gross et al. 2014). Nevertheless, for most ash trees, lifespan is considerably reduced (Skovsgaard et al. 2010).

Due to the threatened existence of ash 


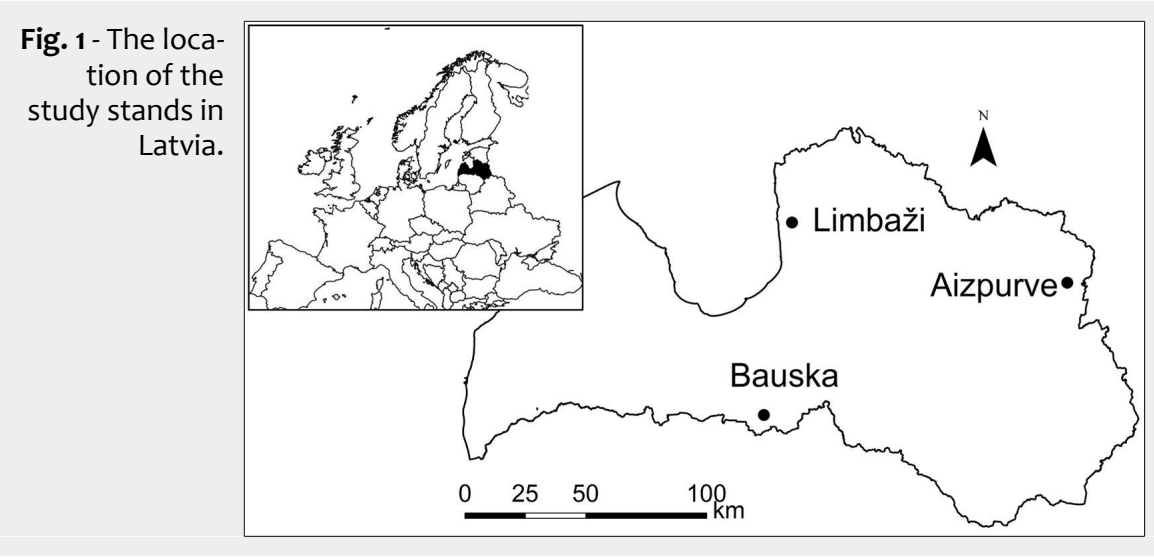

(Pautasso et al. 2013), natural resistance against the pathogen and methods for improving this resistance have been among the most commonly investigated issues regarding the dieback (Kjaer et al. 2012, McKinney et al. 2014). Seasonal dynamics of lesion development, specifically balance between emergence and entering the latent phase, has been shown to be a proxy of the dieback process (Bengtsson et al. 2014). Pliura et al. (2015) concluded that none of the tested provenances or progenies of ash had complete resistance to the infection or development of the disease, yet their susceptibility notably differed. In contrast, McKinney et al. (2014) were more sceptical, arguing that much more time is required for ash to form a resistance to $H$. fraxineus by means of natural selection. Alternatively, varying susceptibility to the dieback might be related to phenological differences in the seasonal cycles of trees and the fungus (McKinney et al. 2011, Bengtsson et al. 2014). Among abiotic factors, seasonal temperature has been shown to significantly affect the development of lesions (Bengtsson et al. 2014);

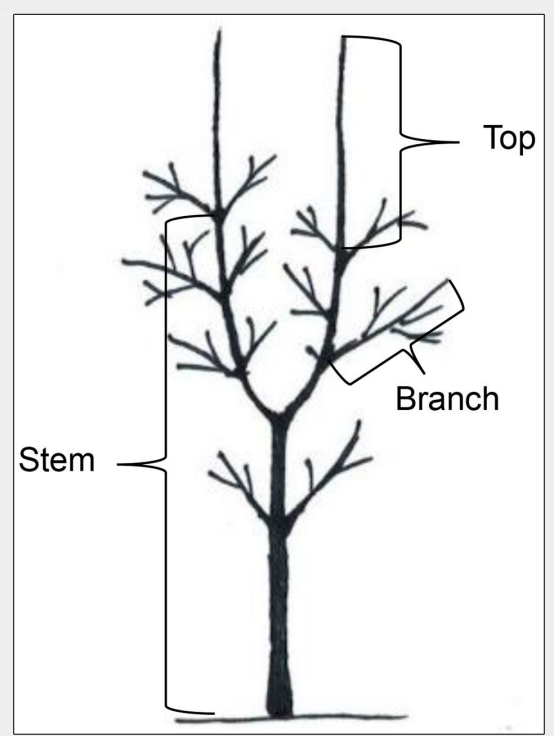

Fig. 2 - The categories used for distribution of lesions according to their location on trees. however, McKinney et al. (2011) observed development and spread of the fungus during the dormant period, suggesting only a partial role of this factor. Hence, more comprehensive information concerning the factors affecting the formation of lesions is required.

The aim of this study was to assess the pattern of lesion development caused by $H$. fraxineus in young ash trees during a growing season. We hypothesised that the development of lesions varied during the vegetation season, and that it was more intense at the beginning of summer when the newly-formed tissues of ash had not yet matured. We also hypothesised that the development of emerging lesions occurred more quickly than that of those already existing.

\section{Materials and methods}

\section{Studied sites}

This study focused on 30 young ash trees (5-8 years of age, according to inventory data) growing in three naturally regenerated post-clear-cut stands in Latvia (Fig. 1) that were dominated by ash in the preceding rotation. These trees were monitored in 2015 from June to September, when the greatest fungal activity is expected (Timmermann et al. 2011, Bengtsson et al. 2014). The stands were fertile and corresponded to the Aegopodiosa site type, according to the national classification by Bušs (1976). Trees grew on flat terrain with a welldrained fertile loamy soil, although water excess occurred during the moist springs. The climate could be classified as moist continental, with the mean annual temper- ature ( \pm standard error) during the most recent three decades ranging from $6.2 \pm 1.6$ to $7.1 \pm 1.5^{\circ} \mathrm{C}$ and the mean annual precipitation ranging from $665 \pm 13.9$ to $618 \pm 12.4$ $\mathrm{mm}$ in the eastern and central parts of Latvia, respectively. The highest monthly precipitation occurred in July and August. The mean temperature in June, July, and August 2015 was $14.9 \pm 0.3,16.9 \pm 0.4$, and $18.7 \pm 0.6{ }^{\circ} \mathrm{C}$ in the central part, and $14.7 \pm$ $0.3,16.2 \pm 0.4$, and $17.6 \pm 0.6{ }^{\circ} \mathrm{C}$ in the eastern part of Latvia, respectively, which were ca. $0.3{ }^{\circ} \mathrm{C}$ cooler than the 30 -year mean values of the respective regions. The precipitation in these months was similar to the long-term mean (ca. 76.9 $\pm 6.5,70.8 \pm 6.2$, and $62.6 \pm 5.1 \mathrm{~mm}$, respectively).

The densities of the Bauska and Aizpurve stands were the greatest (ca. 8000 and 3500 trees ha", respectively), and their compositions were mixed. The Bauska stand was dominated by ash (ca. 5000 trees ha ${ }^{-1}$ ), with an admixture of common aspen (Populus tremula L.) and goat willow (Salix caprea L.; ca. 1500 trees ha ${ }^{-1}$ each). In the Aizpurve stand, ash had a considerably lower density (ca. 1500 trees ha-1 $)$, and was mixed with Norway maple (Acer platanoides L.) and common aspen (ca. 1500 and 500 trees ha ${ }^{-1}$, respectively). In the Limbaži stand, ash was the dominant species (density ca. 1900 trees ha-1), with a small admixture of silver birch (Betula pendula Roth; ca. 200 trees $\mathrm{ha}^{-1}$ ). The dieback process was apparent in all studied stands, as indicated by ash saplings with obvious damage (lesions on top shoots, branches, and stems), confirming the presence of the pathogen. No obvious signs of other diseases or damages were observed.

\section{Sampling and measurements}

In each stand, 10 dominant unsheltered ash saplings with heights of 2.5-3.0 m were selected. At the beginning of the observation, all chosen saplings had one to three lesions that were necroses (discolorations) on stems (40\%), tree tops (32\%), or branches (28\% - Fig. 2). Only trees with a small initial lesion area (the maximum area of the lesions on stems, branches, and tree tops were $37 \mathrm{~cm}^{2}, 5 \mathrm{~cm}^{2}$, and $18 \mathrm{~cm}^{2}$, respectively) were selected. At the beginning of the survey in June, height and diameter at breast height of the sample trees were measured with accuracies of $5 \mathrm{~cm}$ and 0.5 $\mathrm{mm}$, respectively. For four months (from

Tab. 1 - Grades of ash sapling health condition. (AGB): aboveground biomass.

\begin{tabular}{ccl}
\hline Grade & $\begin{array}{c}\text { AGB Damage } \\
\text { (\%) }\end{array}$ & Damage visual characteristics \\
\hline I & $0-10$ & Tree looks healthy or slightly damaged individual leaves \\
\hline II & $11-25$ & $\begin{array}{l}\text { Damaged several leaves, some necroses of the bark } \\
\text { III }\end{array}$ \\
$26-60$ & $\begin{array}{l}\text { Fully damaged/dead separate branches; damaged part of the } \\
\text { foliage; necroses of the bark on large areas }\end{array}$ \\
IV & $61-99$ & $\begin{array}{l}\text { Completely broken up dead part of the crown; partially } \\
\text { damaged the entire crown; live separate branches in secondary } \\
\text { crown }\end{array}$ \\
\hline V & 100 & \begin{tabular}{l} 
Tree is completely dead \\
\hline
\end{tabular} \\
\hline
\end{tabular}


the $10^{\text {th }}$ to the $15^{\text {th }}$ of each month), the health condition of each sapling (quality of crown, and proportion of damaged leaves and shoots) was graded (Tab. 1) according to the methodology reported in Pušpure et al. (2015). In June, all visible lesions on branches and stems were marked on a transparent film. Development of lesions the area of the extension since the last measurement, as well as the emergence of new lesions - was marked on the films at monthly intervals. All measurements were taken by the same person. The location of each lesion, such as necrosis on stems (elongated axis from the apical shoot to the root collar), or necrosis and wilting of top shoots (top shoot down to the uppermost axil) and branches (from stem to top of shoots), was recorded (Fig. 2). For bifurcated trees, all tree tops were considered individually (Fig. 2). After the final survey in September, the damaged parts of the saplings were sampled, bark was removed, and the area of the discoloured wood was marked on the film. To confirm the presence of $H$. fraxineus in the studied trees, samples from the symptomatic material, i.e., from the inner bark or wood from the largest lesions, where the quantity of $\mathrm{H}$. fraxineus mycelium presumably was the highest (Schumacher et al. 2010) were collected. In the Bauska, Limbaži, and Aizpurve stands, seven, six, and four samples were collected, respectively.

In a laboratory, the areas of the lesions from each tree and month were measured on the films with the accuracy of $0.01 \mathrm{~cm}^{2}$ using a TAMAYA digital planimeter PLANIX $10 S$ "Marble". To isolate $H$. fraxineus, samples of the infected material were surface sterilised by submersion in $35 \%$ hydrogen peroxide for 30 seconds and washed twice in distilled water for one minute. After draining, the samples were placed on a Petri dish containing $1 \%$ malt agar and incubated in darkness at $20^{\circ} \mathrm{C}$ for four weeks. As the study was focused on $\mathrm{H}$. fraxineus, any other emerging fungi were mechanically removed from the samples every three days to facilitate development of the target species. The systematic affiliation of the isolate was confirmed microscopically according to Kowalski (2006).

\section{Data analysis}

Based on the rate of extension during the observation season, lesions were divided into three groups: active, inactive, and latent. A lesion was considered active if it had expanded since the last measurement, and considered latent if no expansion occurred during the entire observation period. Newly-emerged lesions (NL), which appeared during the observation period, exhibited patterns of development that differed from those of existing lesions (EL), and were therefore analysed separately. The differences in size and rate of extension of the lesions (per tree) according to their location on a tree (Fig. 2), their age ( $\mathrm{NL}$ or $\mathrm{EL}$ ), overall health condition of the

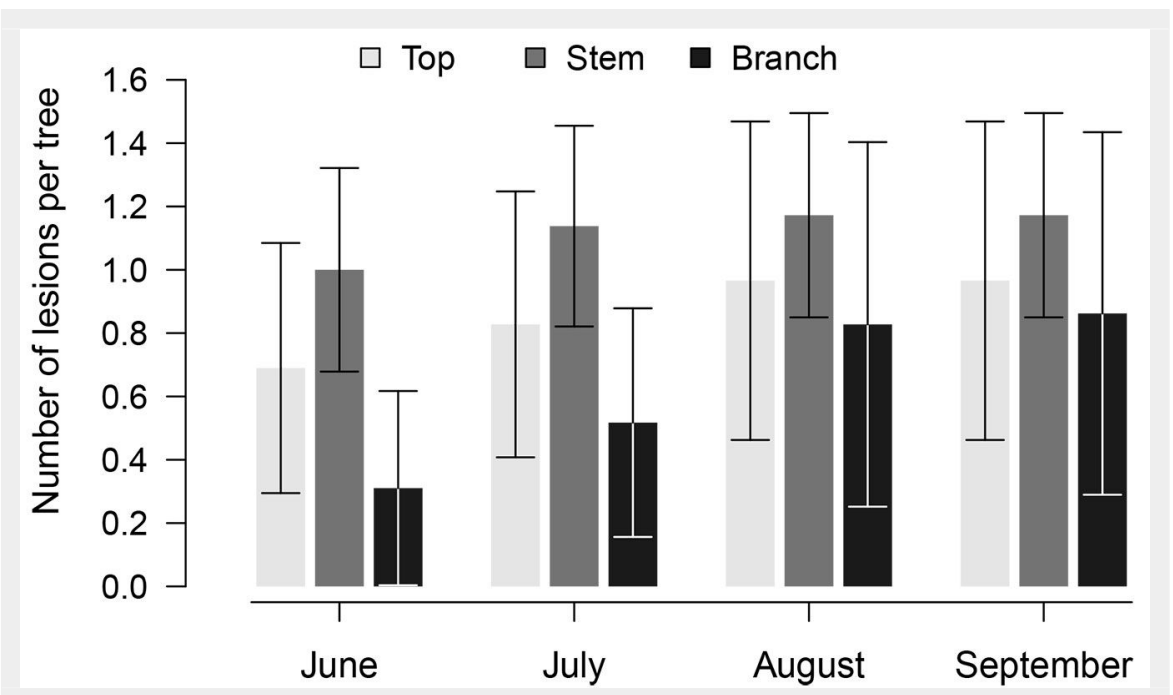

Fig. 3 - The number of the accounted lesions per tree during the observation period according to their location on trees. Whiskers indicate standard errors.

sapling at the beginning of the observation period, and site were evaluated using analysis of variance (ANOVA). A paired-sample t-test was applied to assess differences in the extension of the lesions between the consecutive months, and a Bonferroni transformation was used to adjust the $p$ values of the differences. A generalised linear model (GLM) utilising the binomial distribution of residuals was applied to assess differences in the activity of the lesions (active or inactive, as well as latent or non-latent) according to their location, date of observation, health condition of the sapling, and site. Differences in the number of active/inactive/latent lesions per tree, as well as NL and EL, were assessed according to the same factors via GLM, using a Poisson distribution of the residuals. In all cases, Tukey's honest significant difference post-hoc test was applied to compare the levels of significant factors. Relationships between the lesion area above and below the bark at the end of the survey were quantified through bootstrapped (Johnson 2001) Pearson correlation analysis, whereas relationships between health condition class at the end of the study and sapling height and diameter were quantified via bootstrapped (Johnson 2001) Kendall correlation analysis. The sapling was considered as the statistical unit. All data analyses were conducted in $R$ ver. 3.3.3 ( $R$ Core

Tab. 2 - The proportion of active (expanding since the last observation) lesions during the observation period according to their location on tree. ( $N$ sept): number of accounted lesions in September.

\begin{tabular}{lcccccc}
\hline \multirow{2}{*}{ Period } & \multicolumn{3}{c}{ Existing lesions } & \multicolumn{3}{c}{ Newly emerged lesions } \\
\cline { 2 - 7 } & Top & Stem & Branch & Top & Stem & Branch \\
\hline June (\%) & 58 & 83 & 43 & 33 & 75 & 17 \\
July (\%) & 67 & 83 & 86 & 100 & 100 & 92 \\
August (\%) & 50 & 39 & 29 & 67 & 50 & 42 \\
Total (\% mean) & 58 & 68 & 52 & 67 & 75 & 50 \\
N_sept & 12 & 23 & 7 & 6 & 4 & 12 \\
\hline
\end{tabular}

Team 2016) using the "multcomp" package (Hothorn et al. 2008), with a significance level of $\alpha=0.05$.

\section{Results}

\section{Activity of lesions}

In total, 319 observations of 87 lesions were made. The observed lesions (Fig. 3) were necroses on stems $(39.8 \%$, the mean \pm standard error number of lesions per tree was $1.2 \pm 0.8)$, tree tops $(31.8 \%, 0.9 \pm 0.5$ per tree), and branches (28.4\%, $0.9 \pm 0.3$ per tree). Most of the lesions (67\%) were EL, of which $26 \%$ were latent; NL comprised $33 \%$ of all observed. Among the EL, 50\%, $34 \%$, and $16 \%$ were located on stems, tree tops, and branches, respectively, whereas $17 \%, 28 \%$, and $55 \%$ of the NL appeared on those same parts, respectively. The number of NL significantly ( $p$-value $<0.001)$ differed among months and sites. Overall, NL appeared at the beginning of the observation period ( $45 \%, 52 \%$, and $3 \%$ in June, July, and August, respectively). The number of NL was significantly ( $p$-value $<0.001)$ lower in the Limbaži and Aizpurve stands (12\% and $20 \%$ of the accounted lesions; 0.3 and 0.1 lesions per tree that emerged in June and July, respectively) than in the Bauska stand ( $62 \%$ of the accounted lesions), where 0.7 , 1.3 , and 0.1 lesions per tree emerged in June, July, and August, respectively. $\mathrm{H}$. 


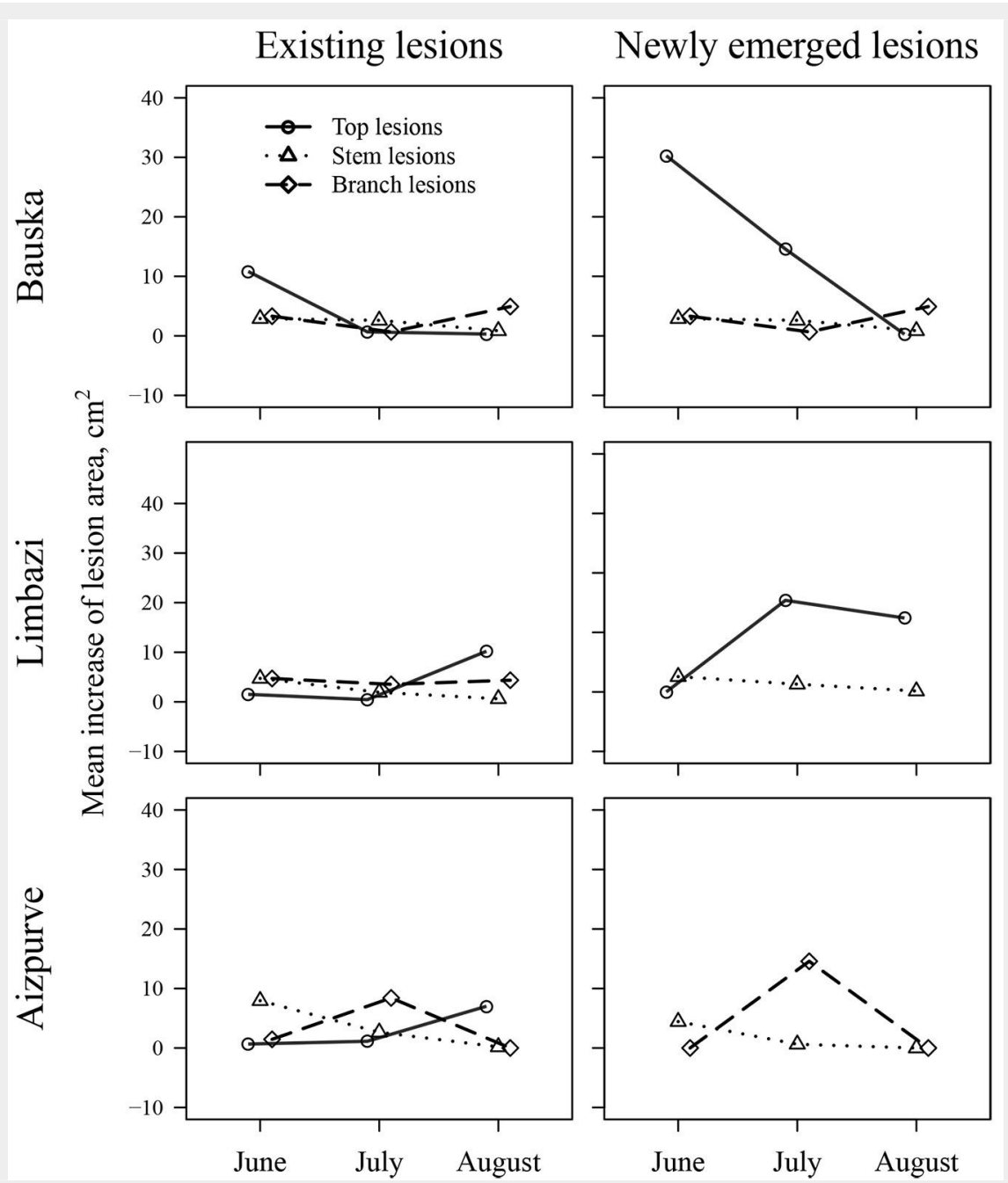

Fig. 4 - The mean monthly increase in area of the lesions existing before the observation period and newly emerging lesions in the studied stands according to the location on trees. The symbols are shifted for clarity.

fraxineus was isolated in six of the 17 samples collected (35\% - four in Bauska and two in Aizpurve).

The mean proportion of latent lesions was similar ( $p$-value $=0.23$ ) among the locations on trees $(25 \pm 10 \%)$, yet it was sig-

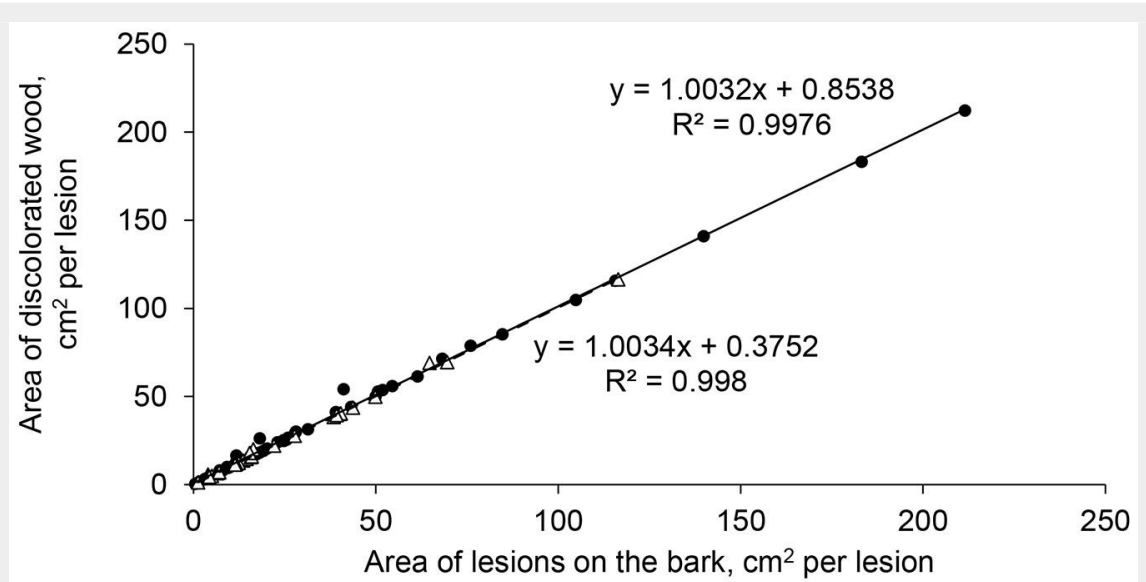

- Existing lesions

$\Delta$ Newly emerged lesions

- Linear (Existing lesions)

- - - Linear (Newly emerged lesions)

Fig. 5 - The relationships between the visible area and area below the bark of the lesions existing before the observation period and newly emerging lesions. nificantly ( $p$-value $=0.007)$ higher in Limbaži than in Bauska (39 $\pm 9 \%$ and $12 \pm 6 \%$, respectively); in the Aizpurve stand, it was intermediate $(30 \pm 11 \%)$. The proportion of active lesions (Tab. 2 ) differed between EL and NL ( $p$-value $<0.01$ ), and among locations on trees ( $p$-value $=0.02)$, and varied during the season, with significant differences observed among months ( $p$-value < 0.001). Nonetheless, the activity of lesions was similar among the stands ( $p$-value $=$ $0.13)$. During the entire observation period, the highest activity was observed for lesions on stems ( 68 and $75 \%$ for EL and NL were active, respectively) and tree tops (58 and $67 \%$, respectively). The activity of lesions on branches was the lowest, as $52 \%$ of $E L$ and $50 \%$ of NL expanded during the observation period. For both EL and NL, activity was the highest in July ( $83 \%$ and $100 \%$, respectively), and then sharply decreased in August (39\% and 50\%, respectively).

\section{Extension of lesions}

During the season, the area of lesions \pm standard error increased from $52.5 \pm 11.3$ $\mathrm{cm}^{2}$ per tree in June to $92.1 \pm 14.7 \mathrm{~cm}^{2}$ per tree (91.9 $\pm 60.1,42.3 \pm 11.5$, and $26.6 \pm 15.9$ $\mathrm{cm}^{2}$ per tree for top, branch, and stem lesions, respectively) at the end of the observation period (Fig. 4). The extension of the lesions was highly significant ( $p$-value < 0.001) until August, but ceased thereafter, similarly across all stands. The mean extension of lesion area significantly differed between EL and NL ( $p$-value < 0.01). During the season, $\mathrm{NL}$ extended by $25.1 \pm 4.8 \mathrm{~cm}^{2}$, whereas EL only expanded by $7.3 \pm 1.1 \mathrm{~cm}^{2}$. The rate of extension of EL was similar among stands ( $p$-value $=0.84)$ and locations on trees ( $p$-value $=0.47 ; 2.48 \pm 0.70$ $\mathrm{cm}^{2}$ per lesion per month). The extension of NL was also similar among the stands $(p$-value $=0.50)$; however, it differed among locations on trees ( $p$-value $=0.02)$. The extension of lesions on the stems was considerably slower than on the branches and tree tops $(1.9 \pm 0.7,7.3 \pm 1.5$, and $14.5 \pm$ $4.1 \mathrm{~cm}^{2}$ per lesion per month, respectively). The development of lesions on the stems and branches culminated in June and July, respectively, similarly for both EL and NL. The patterns of development of EL and NL on tree tops differed; NL had the fastest enlargement after appearance (mostly in June), whereas EL exhibited a maximum extension later in the season (in August; Fig. 4). A strong correlation $(r=0.99)$ between the area of the lesions above and below the bark in late September suggested a clear linear dependence of these variables (Fig. 5). Nevertheless, the difference between the lesion areas below and above the bark was significantly ( $p$-value < 0.001 , by ca. $6 \%$ ) higher for EL than it was for $\mathrm{NL}$ (ca. $2 \%$ ), yet it was similar among stands and locations on trees.

As the season advanced, $28 \%$ of EL and $20 \%$ of NL girdled branches, causing their complete dieback. Some transitions of lesions from tree tops and branches to stems 
were also observed. At the first observation, five necroses on stems coincided with dead branches, whereas in the following months, three lesions from girdled branches expanded onto the stems. The dieback of the infected tops was slightly weaker, as $20 \%$ ( $5 \%$ in June, $15 \%$ in July) and $25 \%$ (in August) of the EL and NL, respectively, girdled tree tops, causing their dieback. Five of the observed 28 tree top lesions expanded onto the stem.

\section{Health condition of trees}

The growing number of lesions and the area they covered decreased the overall health condition of saplings; their health grade increased from 1.6, 1.6, and 1.7 in June to 2.7, 3.2, and 2.9 at the end of the observation period (September) for the Limbaži, Bauska, and Aizpurve stands, respectively. Nevertheless, mortality of the studied saplings was low, as only one sapling in the Aizpurve stand died in August. That sapling was strongly mechanically damaged in July and had an extensive lesion area $\left(215 \mathrm{~cm}^{2}\right)$.

There were no significant relationships between the health grade at the beginning of the observation period and the expansion rate of EL or $\mathrm{NL}$, nor between health grade and the number of lesions, although slight positive tendencies were visible (Fig. 6 ). There was no significant relationship between the number of EL and NL, suggesting a similar probability of a lesion emerging, irrespective of preceding infection. The morphometric parameters showed no effects on the development of lesions, as the correlations between the total lesion area per sapling in September and height, as well as between total lesion area and diameter of the saplings, were not significant $(r=-0.09$ and $0.11, p$-value $=$ 0.55 and 0.47 , respectively). Health condition class in June was negatively affected by tree diameter $(\tau=-0.21, p$-value $=0.01)$, but not by tree height $(\tau=-0.02, p$-value $=$ 0.79).

\section{Discussion}

\section{Agent and occurrence of lesions}

The isolation of $H$. fraxineus confirmed its involvement in the formation of lesions on ash saplings. The proportion of positive samples was intermediate (35\%) in comparison to that found in Sweden (Bengtsson et al. 2014) and lower than that in nurseries in Germany (Schumacher et al. 2010), suggesting the involvement of other agents (Husson et al. 2012). As this study focused on $H$. fraxineus, other agents were not quantified. Alternatively, the low occurrence of the pathogen in samples might be explained by seasonal (McKinney et al. 2011, Bengtsson et al. 2014) and tree-vice (Schumacher et al. 2010) variation in the number of propagules, or by intense surface sterilisation of samples prior to incubation.

Most of the observed lesions were lo-

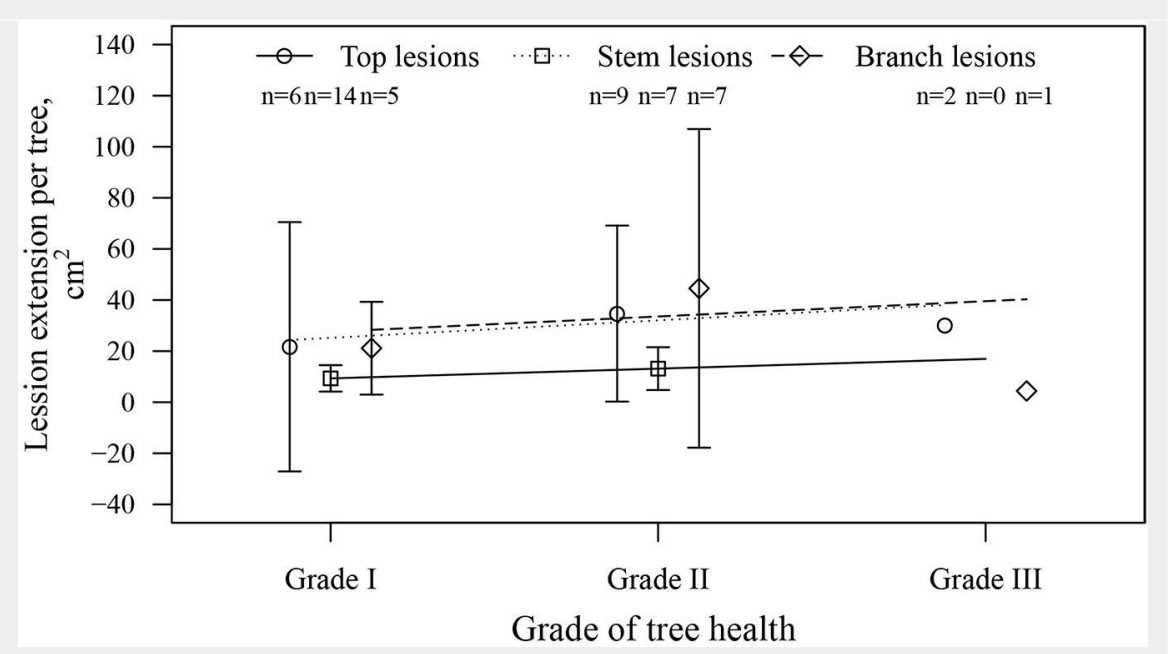

Fig. 6 - The mean increase in the lesion area (extension) per tree during the observation period according to the health grade of saplings in June 2015 (beginning of the observation period). Whiskers indicate standard error (where applicable). ( $n$ ): number of trees.

cated on stems (Fig. 3), which were the largest parts of the trees, and hence featured most EL, including those previously occurring on tops. Considering that propagules of $\mathrm{H}$. fraxineus (Schumacher et al. 2010) infect their host through leaves and shoots (Cleary et al. 2013), most NL were found on branches (twigs) and tops (Fig. 3). The occurrence of NL on the lower parts of stems suggests that infection may have occurred through an alternative pathway (e.g., via lenticels or fine roots - Husson et al. 2012, Fones et al. 2016), but genotyping would be necessary to validate this hypothesis. Nonetheless, there was no visible discoloration of wood below EL on stems leading towards shoots, as observed by Bengtsson et al. (2014), although young hyphae may not be visible (Schumacher et al. 2010).

\section{Lesion activity}

Although sporulation of many pathogenic fungi is synchronised with the biological cycles of their host, $H$. fraxineus has an extended period of spore release (Kirisits \& Cech 2009), indicating a high possibility of infection throughout the season. Most NL emerged in June and July (Fig. 3), however, implying a seasonal pattern, which might be explained by the maturation of leaves and shoots (Schumacher et al. 2010, Timmermann et al. 2011). The majority of $\mathrm{NL}$ appeared on branches (Tab. 2), where most leaves, which are the primary infected organs (Kirisits \& Cech 2009, Kirisits et al. 2009), occurred.

The development of lesions explicitly differed among the stands, as indicated by the number and activity of lesions (Fig. 4). These differences might be related to the structure of the stands, as well as to the connectivity between them (Liepinš et al. 2016), and hence also to the abundance of propagules. The moister microclimate of a denser stand is considered to facilitate de- velopment of the pathogen (Timmermann et al. 2011), hence the occurrence of lesions. Although Bengtsson et al. (2014) and McKinney et al. (2011) suggested a weak effect of temperature on the development of lesions, differences among the stands (Fig. 4) still might be related to local climate. The highest and lowest numbers of active lesions was observed in the Bauska and Limbaži stands, where summers were the warmest and coolest, respectively. The effect of temperature was also supported by the seasonal pattern of lesion development, as the highest activity, particularly for NL, occurred in July (Tab. 2), when the temperature was the warmest (ca. 15-18 $\left.{ }^{\circ} \mathrm{C}\right)$. Previously, the highest activity of $\mathrm{H}$. fraxineus has been observed when the mean temperature is close to $20{ }^{\circ} \mathrm{C}$ (Kowalski \& Bartnik 2010, Timmermann et al. 2011). The sharp decrease in lesion development after August (Fig. 3, Tab. 2) might be linked to shortening of the photoperiod and initiation of cold hardening, which ceases the development of lesions (McKinney et al. 2011). It remains difficult, however, to overtly distinguish the influence of temperature on fungal and tree life-cycles (Bengtsson et al. 2014).

\section{Lesion extension}

The extension of lesions, which could be considered the main process affecting the overall condition of saplings (McKinney et al. 2011), differed between EL and NL, as well as amongst the affected parts of trees, and were modulated by local factors (Fig. 4). The extension of lesions mostly decreased as the season advanced (Fig. 4), similarly to the emergence of NL. Nonetheless, higher rates of extension of NL indicated that after emergence, lesions rapidly grew to a certain minimum size within the first month. Apparently, a month was necessary for ash to partially compartmentalise the development of the pathogen 
(Pallardy 2008), slowing extension of the lesion. Alternatively, this might be connected to the higher activity of younger strains of fungus (Lygis et al. 2016). The opposite was observed for EL on tree tops in two of the three stands, which exhibited maximum extension in August (Fig. 4). This could likely be related to slower compartmentalisation of the pathogen at the cessation of the growing period, when formation of callus is slower (Pallardy 2008). In the Bauska stand, however, EL on tree tops were the most active in June, presumably due to the moister microclimate of the denser stand.

At the end of the observation period, the largest lesions were observed on tree tops, which were the largest shoots. The fastest spread of the pathogen within its host occurs in the stem pith, which is closest to the surface of shoots (Schumacher et al. 2010). In addition, the bark on shoots is thinner, facilitating the extension of lesions (Husson et al. 2012). Larger lesions on top shoots might also be related to microclimatic conditions, as apical shoots receive more atmospheric moisture during the night (dew), particularly in dense stands, as suggested by NL in the Bauska stand (Fig. 4). In the older parts of a tree, hyphae must apparently penetrate wood ray parenchyma (Schumacher et al. 2010), which limits their development, explaining the slower extension of lesions on stems (Fig. 4). The opposite was observed by Bengtsson et al. (2014) in Sweden, likely due to differences in climate and/or tree genetics (Pliura et al. 2011, 2015). Nevertheless, the actual size of lesions (under bark) was larger for EL (Fig. 5), implying some latent extension, as observed by Schumacher et al. (2010) and McKinney et al. (2011). The actual and visible sizes of NL were more similar (Fig. 5), likely because of the rapid extension (Fig. 4).

\section{Health condition of trees}

The intermediate proportion of NL (33\% of the accounted) and low mortality of the affected parts of trees (ca. 22\%) indicated chronic formation of lesions, suggesting a certain resistance to the dieback (Pliura et al. 2015). The presence of latent EL suggested that trees were able to sufficiently compartmentalise the pathogen (Pallardy 2008). In addition, biological limitations (e.g., inactive physical defence) of development (Bengtsson et al. 2014) were observed, as most of the lesions stopped expansion when reaching the shoot base or the main stem. This might be related to the anatomical properties of wood, such as differences in vessel size and lateral connectivity, or pith diameter between the transitions of height increments of consecutive years (Schweingruber 2007). Regarding shoots, this might also be linked to differences in the thickness of primary and secondary bark compared to stem diameter (Husson et al. 2012). Nevertheless, previous studies have shown that the mortality of affected trees increases drastically in subsequent years (Kirisits \& Freinschlag 2011, Pliura et al. 2011, 2015, Bengtsson et al. 2014).

Although the overall health condition of the saplings decreased differently during the observation period, the non-significant relationships between initial health condition and the number and extension of lesions (Fig. 6) suggested comparable infection pressure for all saplings, regardless of previous infection. This was supported by the non-significant relationship between the number of EL and NL in September, indicating the influence of stochastic processes or microclimate. The opposite was observed by McKinney et al. (2011) in Denmark, where susceptibility to the disease appeared to be prevailingly controlled by deterministic factors, such as genetics. Such differences could be related to the milder and more humid climate in Denmark that facilitates development of $H$. fraxineus and extension of lesions (Kowalski \& Bartnik 2010, Timmermann et al. 2011), enhancing the tree-vice differences in susceptibility (Schumacher et al. 2010). Nevertheless, relationships between morphometrics (diameter) and health grade were observed, suggesting that the largest trees were also the healthiest.

\section{Conclusion}

As hypothesised, the development of lesions followed a seasonal pattern that could be linked to meteorological and phenological conditions. The emergence, activity, and extension of lesions was greatest during June and July, when the plant tissue had not yet matured and ambient temperature was close to the optimum for $\mathrm{H}$. fraxineus development. Accordingly, the most rapid extension of the lesions was observed on top shoots, the youngest parts of trees, suggesting that height growth would be notably affected. Differences in the development of lesions amongst the stands indicated effects of climate, as well as local factors (e.g., microclimate); hence, alterations in lesion development might be expected with the changing climate. The extension of newly-emerging lesions was faster than that of existing ones, particularly during the first month of observation, suggesting that approximately one month was necessary for trees to compartmentalise the infection. The development of lesions was not related to the health condition of trees, and a relationship between the number of existing and emerging lesions did not exist, indicating that infection was stochastic. Biological limitations of lesion development were observed, as most lesions remained in the initially-infected parts of trees. The proportion of emerging lesions exceeded the proportion of latent lesions, indicating a progressive decrease in the overall health condition of trees; however, both this proportion and tree mortality appeared to be lower than in other studies. Nonetheless, a longer obser- vation season involving a wider spectrum of sites is required to evaluate the annual cycles in development of the infection, as well as to allow the assessment of secondary infections.

\section{Acknowledgements}

This study was financially supported by the Latvian State Forest project "Dieback and regeneration of ash stands in Latvia" (No 5.5.-5.1_0017 101_14_28) and by the Forest Sector Competence Centre project "Methods and technologies for increasing forest capital value" (No L-KC-11-0004)". We are grateful to anonymous reviewers for their comments and constructive advices.

\section{References}

Bakys R, Vasaitis R, Ihrmark K, Stenlid J (2009). Investigations concerning the role of Chalara fraxinea in declining Fraxinus excelsior. Plant Pathology 58: 284-292. - doi: 10.1111/j.1365-3059. 2008.01977.x

Bengtsson SBK, Barklund P, Brömssen C, Stenlid $J$ (2014). Seasonal pattern of lesion development in diseased Fraxinus excelsior infected by Hymenoscyphus pseudoalbidus. PLoS One 9 (4): e76429. - doi: 10.1371/journal.pone.0076429

Bušs K (1976). Latvijas PSR mežu klasifikacijas pamati [Basis of forest classification in SSR of Latvia]. LRZTIPI, Riga, Latvia, pp. 34. [in Latvian]

Cleary MR, Daniel G, Stenlid J (2013). Light and scanning electron microscopy studies of the early infection stages of Hymenoscyphus pseudoalbidus on Fraxinus excelsior. Plant Pathology 62 (6): 1294-1301. - doi: 10.1111/ppa.12048

Fones HN, Mardon C, Gurr SJ (2016). A role for the asexual spores in infection of Fraxinus excelsior by the ash-dieback fungus Hymenoscyphus fraxineus. Scientific Reports 6: 34638. doi: $10.1038 /$ srep34638

Gross A, Holdenrieder O, Pautasso M, Queloz V, Sieber T (2014). Hymenoscyphus pseudoalbidus, the causal agent of European ash dieback. Molecular Plant Pathology 15 (1): 5-21. - doi: 10.1111/mpp.12073

Hothorn T, Bretz F, Westfall P (2008). Simultaneous inference in general parametric models. Biometrical Journal 50: 346-363.- doi: 10.1002/bi mj.200810425

Husson C, Caël O, Grandjean JP, Nageleisen LM, Marçais B (2012). Occurrence of Hymenoscyphus pseudoalbidus on infected ash logs. Plant Pathology 61: 889-895 - doi: 10.1111/j.1365-30 59.2011.02578.x

Johnson RW (2001). An introduction to bootstrap. Teaching Statistics 23: 49-54. - doi: 10.1111/1467-9639.00050

Kenigsvalde K, Arhipova N, Laivinš M, Gaitnieks T (2010). Ošu bojaeju izraisoša sene Chalara fraxinea Latvija [Fungus Chalara fraxinea as a causal agent for ash decline in Latvia]. Mežzinatne 21 (54): 110-120. [in Latvian]

Kirisits T, Cech TL (2009). Beobachtungen zum sexuellen Stadium des EschentriebsterbenErregers Chalara fraxinea in Österreich [Observations on the sexual stage of the ash dieback pathogen Chalara fraxinea in Austria]. Forstschutz Aktuella 48: 21-25. [in German] 
Kirisits T, Freinschlag C (2011). Ash dieback caused by Hymenoscyphus pseudoalbidus in a seed plantation of Fraxinus excelsior in Austria. Journal of Agricultural Extension and Rural Development 4 (9): 184-191. - doi: 10.5897/JAERD 12.046

Kirisits T, Matlakova M, Mottinger-Kroupa S, Cech TL, Halmschlager E (2009). The current situation of ash dieback caused by Chalara fraxinea in Austria. In: Proceedings of the "IUFRO working party 7.02.02" (Dogmus-Lehtijärvi T ed). Egirdira (Turkey) 11-16 May 2009. SDU Faculty of Forestry Journal, Serial A, Special Issue, pp. 97-119. [online] URL: http://www.citeu like.org/group/15400/article/13549931

Kjaer ED, McKinney LV, Nielsen LR, Hansen LN, Hansen JK (2012). Adaptive potential of ash (Fraxinus excelsior) populations against the novel emerging pathogen Hymenoscyphus pseudoalbidus. Evolutionary Applications 5: 219228. - doi: 10.1111/j.1752-4571.2011.00222.x

Kowalski T, Bartnik C (2010). Morphological variation in colonies of Chalara fraxinea isolated from ash (Fraxinus excelsior L.) stems with symptoms of ash dieback and effects of temperature on colony growth and structure. Acta Agrobotanica 63: 99-106. - doi: 10.5586/aa.20 10.012

Kowalski T (2006). Chalara fraxinea sp. nov. associated with dieback of ash (Fraxinus excelsior) in Poland. Forest Pathology 36 (4): 264-270. doi: 10.1111/j.1439-0329.2006.00453.x

Laivinš M, Priede A, Pušpure I (2016). Spread of Hymenoscyphus fraxineus in Latvia: analysis based on dynamics of young ash stands. Proceedings of the Latvian Academy of Science, Section B 70 (3): 124-130. - doi: 10.1515/prolas2016-0020

Liepinš K, Liepinš J, Matisons R (2016). Growth patterns and spatial distribution of common ash (Fraxinus excelsior L.) in Latvia. Proceedings of the Latvian Academy of Sciences. Section B, Vol 70 (3): 109-115. - doi: 10.1515/prolas-20160018
Lygis V, Prospero S, Burokiene D, Schoebel CN, Marciulyniene D, Norkute G, Rigling D (2016). Virulence of the invasive ash pathogen Hymenoscyphus fraxineus in old and recently established populations. Plant Pathology 66 (5): 783791. - doi: 10.1111/ppa.12635

McKinney LV, Thomsen IM, Kjaer ED, Nielsen LR (2011). Genetic resistance to Hymenoscyphus pseudoalbidus limits fungal growth and symptom occurrence in Fraxinus excelsior. Forest Pathology 42: 69-74. - doi: 10.1111/j.1439-0329.20 11.00725.x

McKinney LV, Nielsen LR, Collinge DB, Kjaer ED (2014). The ash dieback crisis: genetic variation in resistance can prove a long-term solution. Plant Pathology 63 (3): 485-499. - doi: 10.1111/ ppa.12196

Pallardy SC (2008). Physiology of woody plants ( $3^{\text {rd }}$ edn). Elsevier, London, UK, pp. 464.

Pautasso M, Aas G, Queloz V, Holdenrieder O (2013). European ash (Fraxinus excelsior) dieback - a conservation biology challenge. Biological Conservation 158: 37-49. - doi: 10.1016/j. biocon.2012.08.026

Pliura A, Heuertz M (2003). EUFORGEN technical guidelines for genetic conservation and use for common ash (Fraxinus excelsior). Web site. [online] URL: http://www.euforgen.org/publica tions/publication/ifraxinus-excelsiori-technicalguidelines-for-genetic-conservation-and-usefor-common-ash/

Pliura A, Lygis V, Suchockas V, Bartkevičius E (2011). Performance of twenty four European Fraxinus excelsior populations in three Lithuanian progeny trials with a special emphasis on resistance to Chalara fraxinea. Baltic Forestry 17 (1): 17-34. [online] URL: http://www.research gate.net/publication/262599916

Pliura A, Lygis V, Suchockas V, Marčiulyniene D, Suchockas V, Bakys R (2015). Genetic variation of Fraxinus excelsior half-sib families in response to ash dieback disease following simulated spring frost and summer drought treatments. iForest 9: 12-22. - doi: 10.3832/ifor1514-
008

Pušpure I, Gerra-Inohosa L, Arhipova N (2015). Quality assessment of European ash Fraxinus excelsior L. genetic resource forests in Latvia. Proceedings of the $21^{\text {st }}$ Annual International Scientific Conference Research for Rural Development 2015 (2): 37-43. [online] URL: http:// www.researchgate.net/publication/295812650 R Core Team (2016). R: A language and environment for statistical computing. R Foundation for Statistical Computing, Vienna, Austria. [online] URL: http://www.R-project.org/

Schumacher J, Kehr R, Leonhard S (2010). Mycological and histological investigations of Fraxinus excelsior nursery saplings naturally infected by Chalara fraxinea. Forest Pathology 40: 419429. - doi: 10.1111/j.1439-0329.2009.00615.x

Schweingruber $\mathrm{FH}$ (2007). Wood structure and environment. Springer, Berlin, Germany, pp. 237. [online] URL: http://books.google.com/ books?id=t5fVEqRnyjoC

Skovsgaard JP, Thomsen IM, Skovsgaard IM, Martinussen T (2010). Associations among symptoms in even-aged stands of ash (Fraxinus excelsior L.). Forest Pathology 40 (1): 7-18. - doi: 10.1111/j.1439-0329.2009.00599.x

Thomsen IG, Skovsgaard JP (2012). Silvicultural strategies for forest stands with ash dieback. Fortschutz Aktuell 55: 18-20.

Timmermann V, Brja I, Hietala AM, Kirisits T, Solheim $H$ (2011). Ash dieback: pathogen spread and diurnal patterns of ascospore dispersal, with special emphasis on Norway. EPPO Bulletin 41: 14-20. - doi: 10.1111/j.1365-2338.2010.02 429.x

Vasiliauskas R, Bakys R, Lygis V, Barklund P, Ihrmark K, Stenlid J (2006). Fungi associated with the decline of Fraxinus excelsior in the Baltic States and Sweden. In: "Possible limitation of dieback phenomena in broadleaved stands" (Oszako T, Woodward S eds). Forest Research Institute, Warsaw, Poland. pp. 45-53. 